\title{
CARACTERIZAÇÃO DE PARÂMETROS FÍSICOS, QUÍMICOS E BIOLÓGICO EM AMBIENTE HIPERSALINO, ESTUÁRIO DO RIO PISA SAL (GALINHOS, RIO GRANDE DO NORTE, BRASIL).
}

\author{
Marilene Felipe SANTIAGO ${ }^{1}$ \\ José Zanon de Oliveira PASSAVANTE $^{1}$ \\ Maria da Glória Gonçalves da SILVA-CUNHA ${ }^{1}$ \\ 1 - Departamento de Oceanografia - UFPE \\ marilenesantiago@yahoo.com.br
}

Recebido: 31/04/2005

Aceito: $15 / 05 / 2005$

\section{RESUMO}

O estuário do rio Pisa Sal, localizado no ecocomplexo de Galinhos-Guamaré, é utilizado pela Fazenda Camarus como fonte de abastecimento e drenagem de seus viveiros. A presente pesquisa baseou-se em avaliar a biomassa fitoplanctônica e parâmetros físico-químicos como indicadora da qualidade ambiental, para definir a influência de tais atividades no meio ambiente. As amostragens foram feitas em três estações fixas do referido estuário, nos períodos de estiagem (setembro, novembro/02, janeiro, maio e julho/03) e chuvoso (março/03), durante as baixa-mares e preamares diurnas de um mesmo dia, nas marés de sizígia. Para isto, foram analisados parâmetros climatológicos (temperatura, umidade relativa do ar, precipitação, insolação, evaporação, velocidade e direção do vento), hidrológicos (maré, profundidade, transparência da água, salinidade, $\mathrm{pH}$ e oxigênio dissolvido) e biológico (clorofila $a$ ). Além, do coeficiente de extinção da luz, saturação do oxigênio dissolvido e Análise dos Componentes Principais (ACP). Os resultados analisados demonstrou que o estuário do rio Pisa Sal é hipersalino, com forte influência marinha, e apesar do elevado valor do oxigênio dissolvido, o meio ambiente é eutrófico.

Palavras-chave: Estuário do Rio Pisa Sal, hipersalino, clorofila $a$, eutrófico.

\section{ABSTRACT \\ Caracterization of physical, chemical and biological parameters in environment hyperhaline, rio Pisa Sal river estuary (Galinhos, Rio Grande do Norte, Brasil).}

The environments at the Northeast coast of Rio Grande do Norte State are under strong anthropic stress (mainly oil exploration, salt production and marine shrimp culture expansion etc). The present study was conducted in the Pisa Sal River estuary, which belongs to Galinhos-Guamaré ecocomplex, and provides the main water supply and drainage to the Camarus shrimp culture farm. The present research was carried out to assess the influence of these activities on phytoplankton biomass along with the abiotic parameters as environmental quality indicators. Sampling was made in three fixed stations during the dry (September, November/02, January, May, July/03) and rainy (March/03) seasons, at the diurnal low and high tides, in a spring tide. Climatological (temperature, humidity, rainfall, insolation, evaporation, wind velocity and direction) and hydrological (tides, 
depth, water salinity, $\mathrm{pH}$ and dissolved oxygen) data were collected to correlate with the biological (chlorophyll $a$ ) data. Besides, the light extinction coefficient, the dissolved oxygen saturation rate, and the observed in Principal Component Analysis (PCA). The analyzed results show that the Pisa Sal River estuary is hyperhaline, with a strong marine influence, and although the dissolved oxygen is high the environment is eutrophic.

Key-words: Pisa Sal river estuary, hyperhaline, chlorophyll $a$, eutrophic.

\section{INTRODUÇÃO}

Do ponto de vista da biodiversidade, a zona costeira possui uma série de atributos singulares que vão qualificá-la como uma situação geográfica ímpar, pois acolhe quadros naturais particulares de alta riqueza e relevância ecológica, que as qualifica como importantes fontes de recurso (MMA, 1996).

Sob tais aspectos, destaca-se o ambiente estuarino que são áreas férteis e podem produzir grandes quantidades de matéria orgânica, constituindo via de acesso importante para o interior do continente e suas águas são renovadas periodicamente sob influência da maré (MIRANDA et al., 2002).

Entretanto, é indispensável determinar o ambiente estuarino, levando-se em consideração sua funcionalidade, ou seja, considerar como estuários àqueles sistemas que apresentam processos típicos de estuários, independentemente do número de conexões com o mar que eles apresentem, podendo sua conexão ser feita livremente com o mar, ou através de ilhotas, barra de areia etc. Como, também, a água do mar ser ou não mensuravelmente diluída pela água doce (BROCE, 1994).

Nessa linha, algumas lagunas e muitos ditos braços de mar são ambientes costeiros de transição e podem ser genericamente classificados de zonas estuarinas. Por ter os mesmos a gênese contemporânea à dos estuários, o planejamento de utilização e estudos são baseados no conhecimento do funcionamento dos estuários, uma vez que a dinâmica estuarina é razoavelmente bem conhecida (GEOPHYSICS STUDY COMMITTEE, 1997 apud MIRANDA et al., op cit).

Como é o caso do Sistema Estuarino de Galinhos-Guamaré, na região litorânea do Estado do Rio Grande do Norte, que vem sendo alvo da intervenção antrópica, apresentando uma ampla e intensiva exploração petrolífera e salineira, e recentemente uma grande expansão da carcinicultura, em substituição à atividade salineira. E, apesar da baixa densidade populacional das cidades de Guamaré e Galinhos, parte das residências utiliza o rio e o mar para desfazer-se de seus resíduos domésticos, colocando em risco de contaminação os ambientes aqüíferos.

Estes ambientes apresentam grande fragilidade e vulnerabilidade, do ponto de vista ambiental, às intervenções antrópica, decorrentes da complexidade dos mesmos podem ser resultantes da intervenção terra-ar-água (GRIGIO et al., 2003), sendo os mesmos, segundo MMA (op cit), áreas altamente comprometidas.

Considerando estes motivos, o presente trabalho teve como objetivo conhecer a variabilidade natural de alguns parâmetros oceanográficos (físico, químico e biológico) para efeito de qualificação da água no estuário do rio Pisa Sal.

\section{DESCRIÇÃO DE ÁREA}

O Estado do Rio Grande do Norte possui uma região litorânea de $11.888 \mathrm{~km}^{2}$ e uma extensão de 410km (IDEMA, 1999). Neste cenário encontram-se vários canais de maré, formando ambientes hipersalinos, sendo composto, principalmente, pelos rios Porto do Campim, Cumurupim, Galinhos, Pisa Sal, Pratagil e Tomás nos municípios de Galinhos e Guamaré (Fig. 1).

Tropical Oceanography, Recife, v. 33, n. 1, p. 39-55, 2005. 


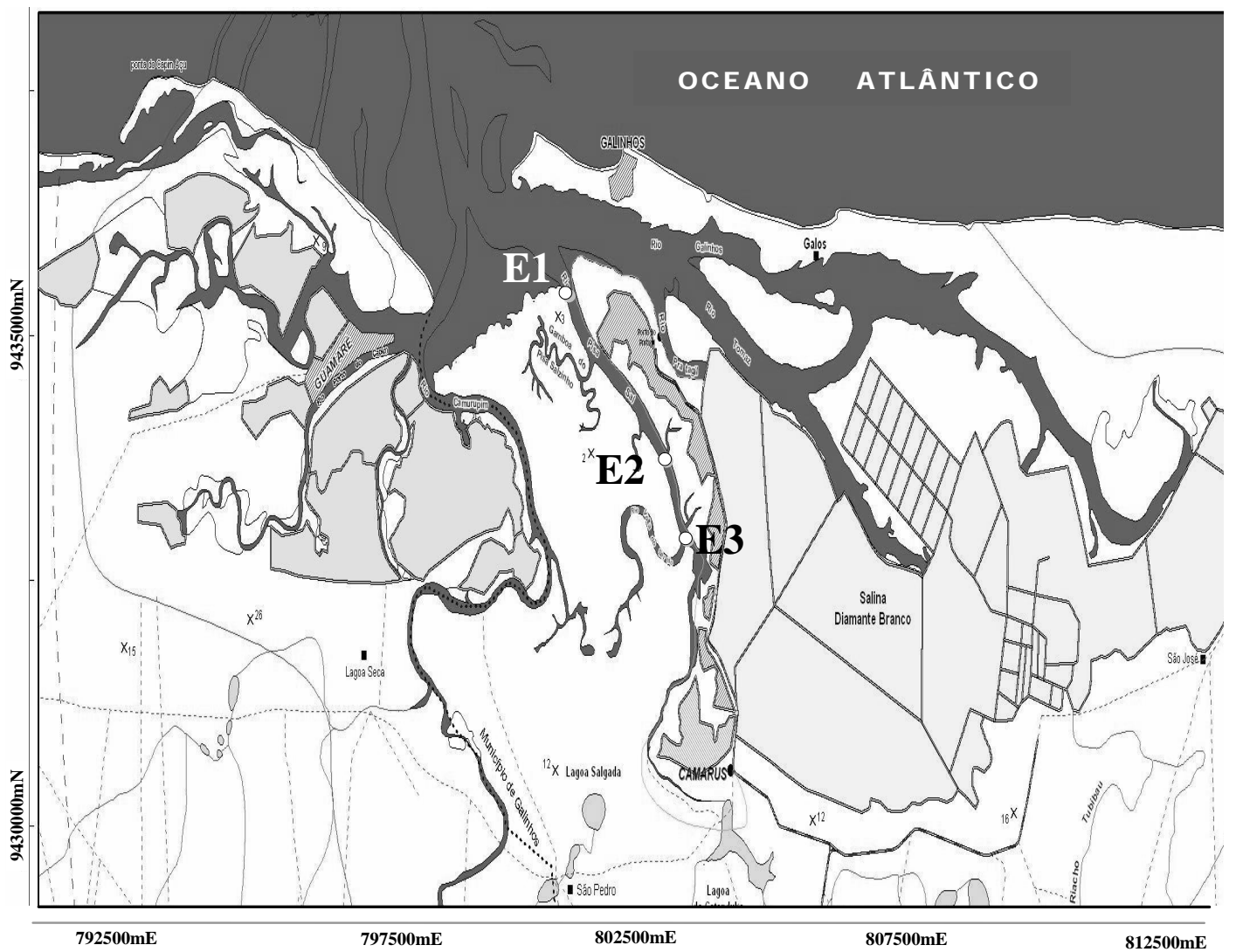

Figura 1 - Sistema Estuarino de Galinhos e Guamaré, identificando as estações de coleta no rio Pisa Sal, Galinhos (RN, Brasil). Fonte: Camarus Aquacultura do Nordeste Ltda.

No município de Galinhos destaca-se o estuário do rio Pisa Sal, com 6,9km de extensão, e talvez a entrada de água doce se dê apenas pela drenagem pluvial e afloramento dos poucos lençóis freáticos. A sua desembocadura ocorre diretamente no mar, juntamente com os outros rios, desaguando no oceano Atlântico.

O curso do estuário do rio Pisa Sal apresenta uma forma no sentido sudeste-noroeste. Na margem direita, localiza-se a Fazenda Camarus, que capta e descarta a água utilizada pelo empreendimento para o cultivo de camarão marinho Litopenaeus vannamei Boone, 1931

De acordo com a classificação de Köppen, o clima dominante na área é o tipo BSwh', clima seco com chuva de verão (ANDRADE; LINS, 1971), com precipitação escassa, com curto período de 2 meses - março à abril (COUTINHO, 1991), apresentando uma média pluviométrica anual de 600mm, por causa do Anticiclone do Atlântico e Zona de Convergência Intertropical, definida pela convergência dos ventos alísios dos Hemisférios Norte e Sul (GRIGIO et al., 2003). Também, deve-se as anomalias da temperatura da superfície do mar sobre o oceano Atlântico pela atuação do El Niño e La Niña.

Tropical Oceanography, Recife, v. 33, n. 1, p. 39-55, 2005. 
Esta região é caracterizada por grande incidência de energia luminosa, regime térmico uniforme, temperaturas elevadas e suaves variações ao longo do ano, provocadas pela baixa latitude, altitude local e a forte influência oceânica (ECOPLAN, 1990 apud CESTARO, 1994).

A temperatura do ar, segundo Aragão (2000), tem média anual de $26,8^{\circ} \mathrm{C}$, com uma amplitude das médias mensais de $3,2^{\circ} \mathrm{C}$. A umidade relativa do ar diário é da ordem de $70 \%$, sendo menor nos meses de junho a novembro, coincidindo com a estação de baixa pluviosidade, e a insolação atinge em média 2.600 horas/ano, o que equivale a 7,1 horas diária de luz solar incidindo sobre o solo (GUEDES, 2002 e SILVEIRA, 2002 apud GRIGIO et al., op cit).

Nesta área, os ventos sopram predominantemente de SE (entre os meses de maio-agosto) de E (setembro-abril) e NE (abril-setembro), com velocidade média anual dos ventos é de $5,7 \mathrm{~m} . \mathrm{s}^{-1}$. As menores velocidades mensais ocorrem nos meses de março à abril, enquanto as maiores ocorrem entre setembro e outubro (SILVEIRA, 2002 apud GRIGIO, op cit).

\section{MATERIAL E MÉTODOS}

As amostras utilizadas no presente trabalho foram coletadas na camada superficial da água no estuário do rio Pisa Sal, Galinhos (RN), em 3 estações fixas (Fig. 1), bimestralmente, nos períodos de estiagem (setembro, novembro/02, janeiro, maio e julho/03) e chuvoso (março/03), obedecendo ao ritmo da BM (baixa-mar) e PM (preamar) diurnas, de um mesmo dia, na maré de sizígia.

Os dados climatológicos foram oriundos da Estação de Meteorologia de Macau (RN), distante $57 \mathrm{~km}$ da área em estudo, pertencente ao Instituto Nacional de Meteorologia. Foram obtidos dados referentes à temperatura do $\operatorname{ar}\left({ }^{\circ} \mathrm{C}\right)$, a umidade relativa do ar $(\%)$, a precipitação pluviométrica $(\mathrm{mm})$, a insolação total $(\mathrm{h})$, a evaporação total $(\mathrm{mm})$, a velocidade média do vento $\left(\mathrm{m} . \mathrm{s}^{-1}\right)$ para 0 período de setembro/02 à julho/03 e a direção do vento ( $1^{\mathrm{a}}$ e $2^{\mathrm{a}}$ predominantes), por problemas técnicos da Estação Meteorológica, só foram fornecidos os dados dos primeiros meses de coleta (setembro e novembro/02 e janeiro/03).

Os hidrológicos compreenderam a profundidade local, a transparência da água (disco de Secchi), o coeficiente de extinção da luz foi calculada a partir dos resultados obtidos com a tomada da transparência da água, utilizando a fórmula de Poole e Atkins (1929).

Com relação a temperatura, o potencial hidrogeniônico $(\mathrm{pH})$ da água foram aferidos com um aparelho digital de marca Oaklon, a salinidade, um refratômetro e o oxigênio dissolvido na água foi através do método de Winkler, modificado para água do mar por Carritt e Carpenter, apud Grasshoff, Enhardt e Kremling (1983).

Posteriormente foi correlacionado os dados de temperatura, salinidade e oxigênio dissolvido, com o auxílio da tabela padrão International Oceanography Tables (UNESCO, 1973) para obtenção da taxa de saturação do oxigênio dissolvido na água.

A determinação da clorofila $a$ foi realizada através do método espectrofotométrico descrito por Teixeira (1973), para os cálculos foi aplicada a equação apresentada por Strickland e Parsons (1972).

Para a Análise dos Componentes Principais (ACP) foi utilizado o programa computacional NTSYS (Numerical Taxonomy and Multivariate Analysis System) da Metagraphics Software Corporation, Califórnia - USA.

Tropical Oceanography, Recife, v. 33, n. 1, p. 39-55, 2005. 


\section{RESULTADOS}

Ao analisar os parâmetros climatológicos observou-se, uma variação sazonal ao longo dos meses com aumento gradativo a partir de novembro/02, atingindo valores máximos de precipitação pluviométrica em março e abril/03 voltando a decrescer nos meses restantes. Tendo uma relação direta da umidade relativa com a precipitação pluviométrica e inversa a temperatura do ar e a evaporação, com alta insolação. Apesar da lacuna ocorrida, a ocorrência do vento mais brando foi, no final do período de estiagem e, não houve uma predominância em relação a direção dos ventos, indicando que a área sofre forte influência, com velocidade mínima de 4,5m/ $\mathrm{s}^{-1}$ (Tab. 1).

Tabela 1 - Variação dos parâmetros climatológicos, registrada na Estação Meteorológica de Macau (Rio Grande do Norte, Brasil).

\begin{tabular}{cccccccc}
\hline Ano/mês & $\begin{array}{c}\text { Precipitação } \\
\text { total (mm) }\end{array}$ & $\begin{array}{c}\text { Temperatura } \\
\left({ }^{\mathbf{O}} \mathbf{C}\right)\end{array}$ & $\begin{array}{c}\text { Umidade } \\
\text { relativa } \\
(\mathbf{\%})\end{array}$ & $\begin{array}{c}\text { Evaporação } \\
\text { total }(\mathbf{m m})\end{array}$ & $\begin{array}{c}\text { Insolação } \\
\text { total } \\
(\text { Hora) }\end{array}$ & $\begin{array}{c}\text { Velocidade } \\
\text { do vento } \\
\left(\mathbf{m} . \mathbf{s}^{-1}\right)\end{array}$ & $\begin{array}{c}\text { Direção } \\
\text { do } \\
\text { vento }\end{array}$ \\
\hline $\mathbf{2 0 0 2}$ & & & & & & & \\
Set. & 0,0 & 27,5 & 68 & 113,8 & 288,6 & 6,0 & $\mathrm{E} / \mathrm{NE}$ \\
Out. & 0,0 & 27,9 & 65 & 125,7 & 289,4 & 6,4 & $\mathrm{SE} / \mathrm{E}$ \\
Nov. & 0,0 & 28,1 & 68 & 108,6 & 280,2 & 6,0 & $\mathrm{E} / \mathrm{SE}$ \\
Dez. & 24,8 & 28,4 & 70 & 100,3 & 278,0 & 5,7 & $\mathrm{E} / \mathrm{N}$ \\
$\mathbf{2 0 0 3}$ & & & & & & & \\
Jan. & 103,8 & 28,1 & 73 & 86,7 & 225,9 & 4,5 & $\mathrm{NE} / \mathrm{N}$ \\
Fev. & 44,7 & 28,4 & 74 & 86,4 & 175,0 & 4,7 & $\mathrm{NE} / \mathrm{N}$ \\
Mar. & 152,8 & 28,2 & 78 & 77,7 & 173,9 & $\ldots$ & $\mathrm{NE} / \mathrm{E}$ \\
Abr. & 155,9 & 28,4 & 78 & 69,5 & 185,9 & $\ldots$ & $\mathrm{NE} / \mathrm{SE}$ \\
Maio & 46,4 & 28,2 & 73 & 84,8 & 197,6 & $\ldots$ & $\mathrm{SE} / \mathrm{NE}$ \\
Jun. & 28,4 & 27,9 & 71 & 99,1 & 200,4 & $\ldots$ & $\mathrm{SE} / \mathrm{NE}$ \\
Jul. & 2,0 & 27,7 & 66 & 118,9 & 219,7 & $\ldots$ & $\mathrm{SE} / \mathrm{E}$ \\
\hline
\end{tabular}

O valor mínimo da altura da maré, registrado foi de $0,12 \mathrm{~m}$, e o máximo de $0,90 \mathrm{~m}$ durante as baixa-mares, apresentando uma média geral de $0,66 \mathrm{~m}$ e amplitude de $0,78 \mathrm{~m}$. E, as preamares caracterizaram-se com valor mínimo de $2,00 \mathrm{~m}$ e máximo $2,70 \mathrm{~m}$, com média 2,43m e a amplitude de 0,70m (Fig. 2).

A profundidade mínima registrada, durante a baixa-mar, foi 2,70m, a máxima de 5,90m, apresentando uma média geral de 4,49m e amplitude de 3,20m. E, a preamar caracterizou-se com valor mínimo de 5,40m e máximo 8,10m, com média 6,70m e a amplitude de 2,70m (Fig. 3).

Tropical Oceanography, Recife, v. 33, n. 1, p. 39-55, 2005. 


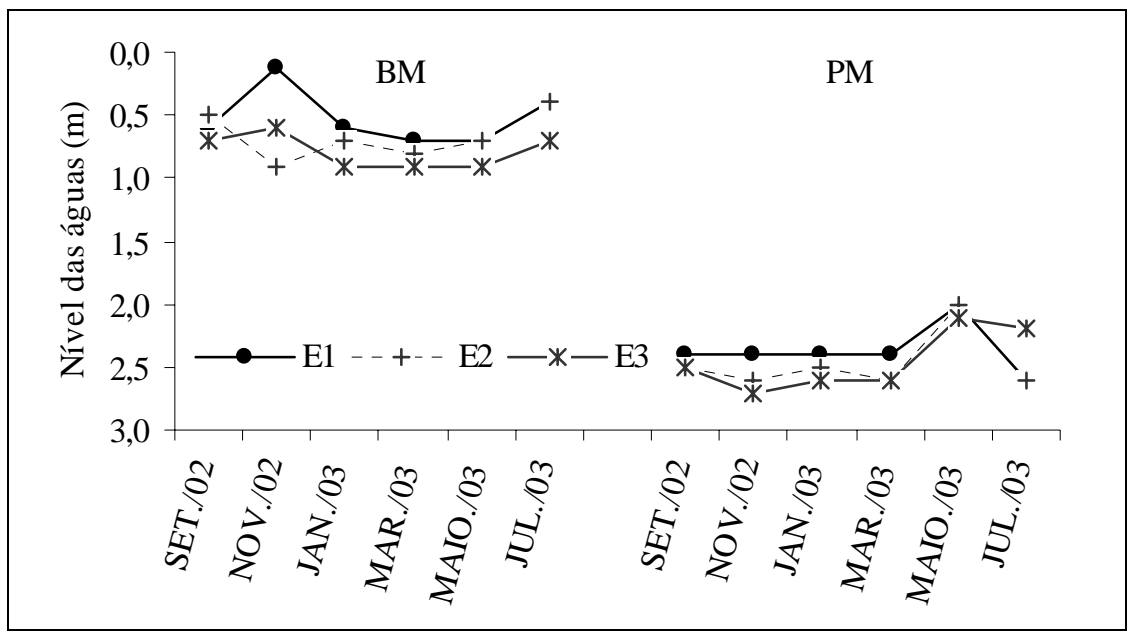

Figura 2 - Variação do nível das águas (m) nas estações 1, 2 e 3, durante as baixa-mares e preamares, nos períodos de estiagem e chuvoso, no estuário do rio Pisa Sal, Galinhos (RN, Brasil).

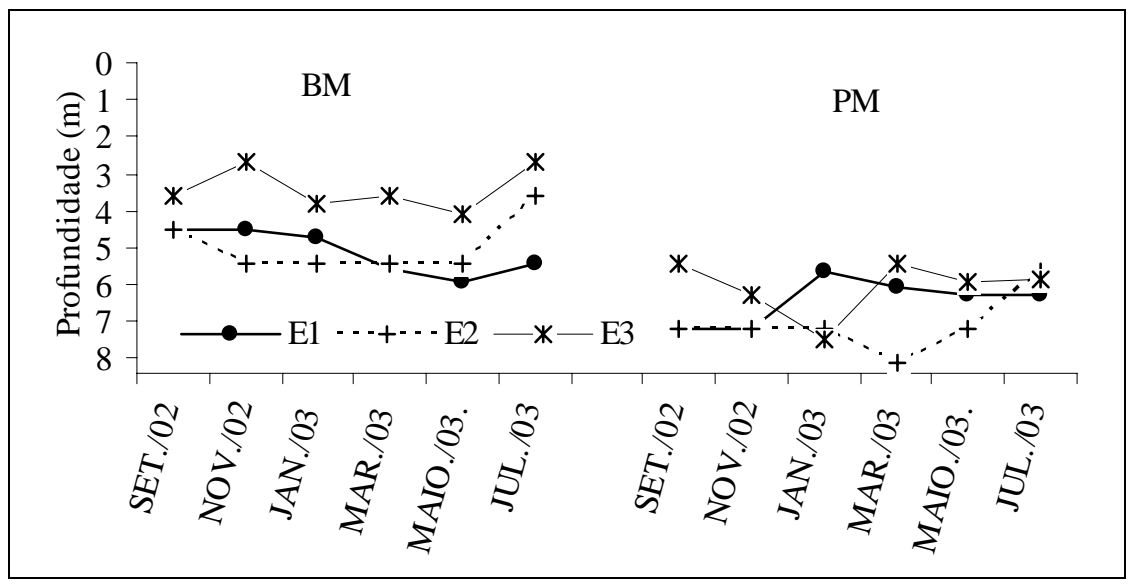

Figura 3 - Variação da profundidade local (m) nas estações 1, 2 e 3, durante as baixa-mares e preamares, nos períodos de estiagem e chuvoso, no estuário do rio Pisa Sal, Galinhos (RN, Brasil).

A transparência da água apresentou uma variação sazonal, com valores mínimos de 0,75m (correspondendo a um coeficiente de extinção de luz de 2,27) registrado na estação 2, durante a preamar de setembro/02 e valor máximo de 3,50m (correspondendo a um coeficiente de extinção de luz de 0,48 ) verificado durante o mês de julho/03, durante a preamar. Os valores de transparência da água apresentaram-se sempre superiores na baixa-mar, durante o período de pesquisa, com exceção dos meses de maio e julho/03 (Fig. 4 e 5). 


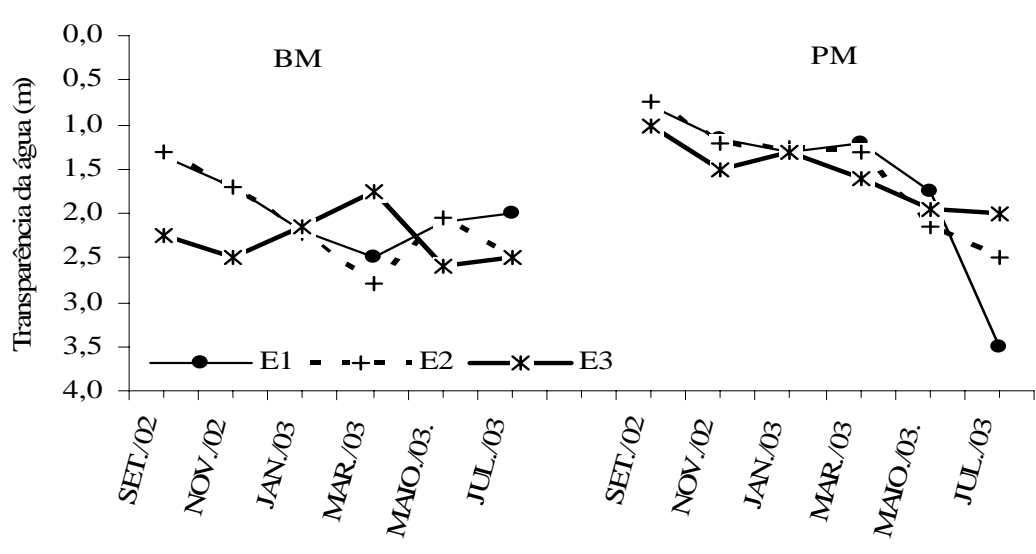

Figura 4 - Variação da transparência da água (m) nas estações 1, 2 e 3, durante as baixa-mares e preamares, nos períodos de estiagem e chuvoso, no estuário do rio Pisa Sal, Galinhos (RN, Brasil).

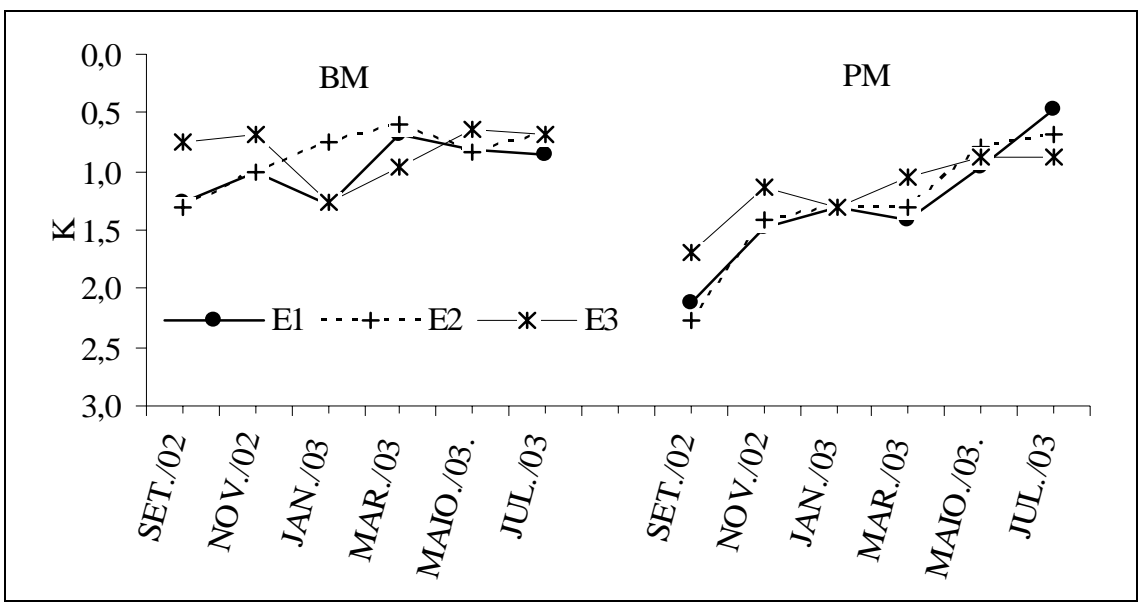

Figura 5 - Variação do coeficiente de extinção de luz nas estações 1, 2 e 3, durante as baixa-mares e preamares, nos períodos de estiagem e chuvoso, no estuário do rio Pisa Sal, Galinhos (RN, Brasil).

A temperatura da água não apresentou grandes diferenças espaciais, sendo a amplitude térmica $3,8^{\circ} \mathrm{C}$, a mínima registrada foi de $26,0^{\circ} \mathrm{C}$ medida em setembro/02 na baixa-mar e a máxima registrada de $29,8^{\circ} \mathrm{C}$, medida em janeiro/03 na baixa-mar, registrando uma média de $27,94^{\circ} \mathrm{C}$ (Fig. $6)$. 


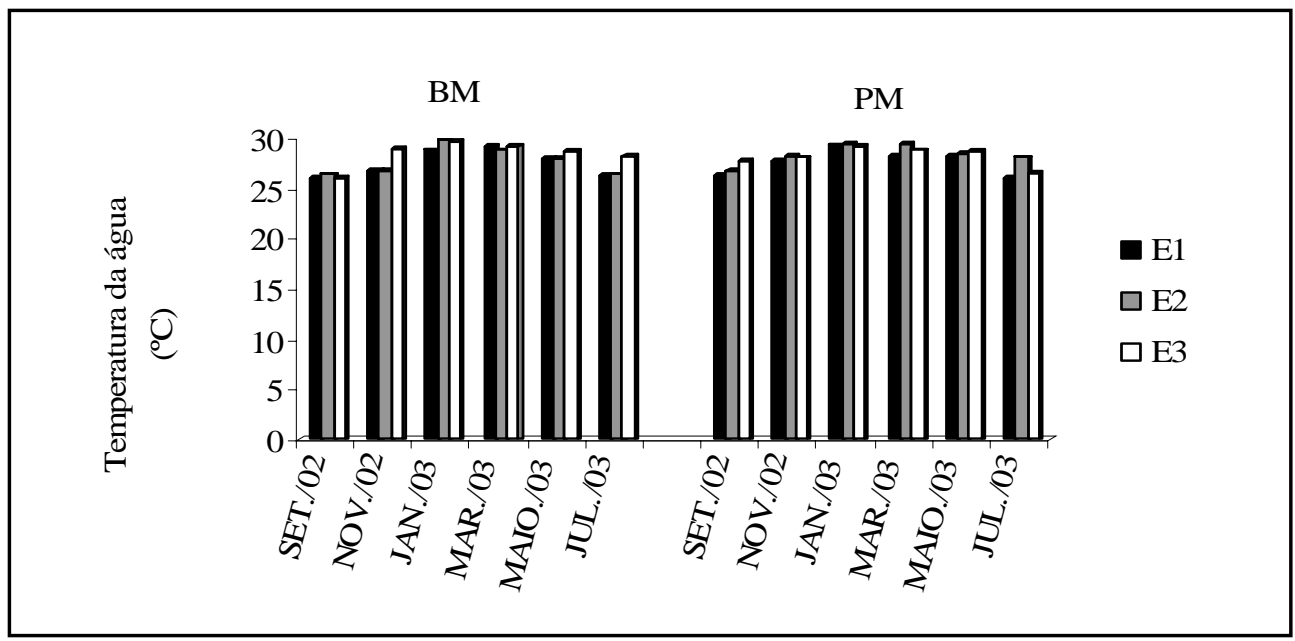

Figura 6 - Variação da temperatura da água $\left({ }^{\circ} \mathrm{C}\right)$ nas estações 1,2 e 3, durante as baixa-mares e preamares, nos períodos de estiagem e chuvoso, no estuário do rio Pisa Sal, Galinhos (RN, Brasil).

A salinidade, apresentou-se valores elevados em todas as marés. Os valores mostraram diferenças pequenas entre a baixa-mar e preamar, durante todo o período pesquisado com amplitude de 7,00ups e a média geral de 38,17ups. O valor mínimo de 34,00ups foi registrado na preamar da estação 2, no mês de março/03. O valor máximo de 41,00ups foi verificado nas baixamares da estação 1 , no mês de janeiro/03 da estação 2, no mês de novembro/02 e estação 3, no mês de novembro/02 e preamar de julho/03 (Fig. 7).

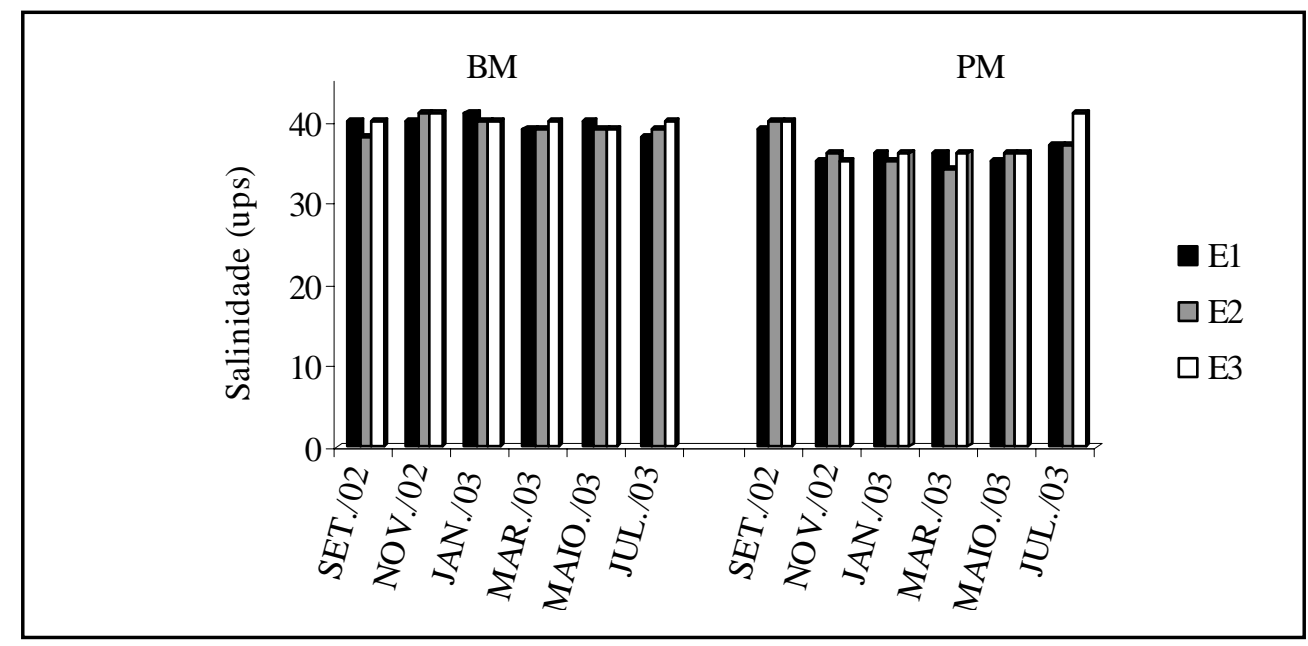

Figura 7 - Variação da salinidade da água (ups) nas estações 1, 2 e 3, durante as baixa-mares e preamares, nos períodos de estiagem e chuvoso, no estuário do rio Pisa Sal, Galinhos (RN, Brasil).

Tropical Oceanography, Recife, v. 33, n. 1, p. 39-55, 2005. 
Durante todo o período de estudo, os valores do $\mathrm{pH}$ oscilaram entre 7,00 encontrado no mês de julho/03, e 8,58 em setembro/02 na estação 2 e maio/03 da estação 3, todos durante a preamar, mantendo-se portanto, sempre alcalino, onde média geral foi de 8,24 e uma amplitude de 0,92 (Fig. 8).

De modo geral os teores de oxigênio dissolvido na água do mar apresentaram um valor mínimo de 3,73ml. $\mathrm{L}^{-1}$ (equivalendo a 82,89\% de saturação de oxigênio) registrado na baixa-mar no mês de setembro/02 na estação 1 e o máximo de $12,40 \mathrm{ml}^{-L^{-1}}$ (283,10\% de saturação de oxigênio) na preamar em janeiro/03 na estação 3, uma amplitude de $8,67 \mathrm{ml}^{-L^{-1}}(200,21 \%$ de saturação de oxigênio) e média de 7,01 (159,49\% de saturação de oxigênio) (Fig. 9).

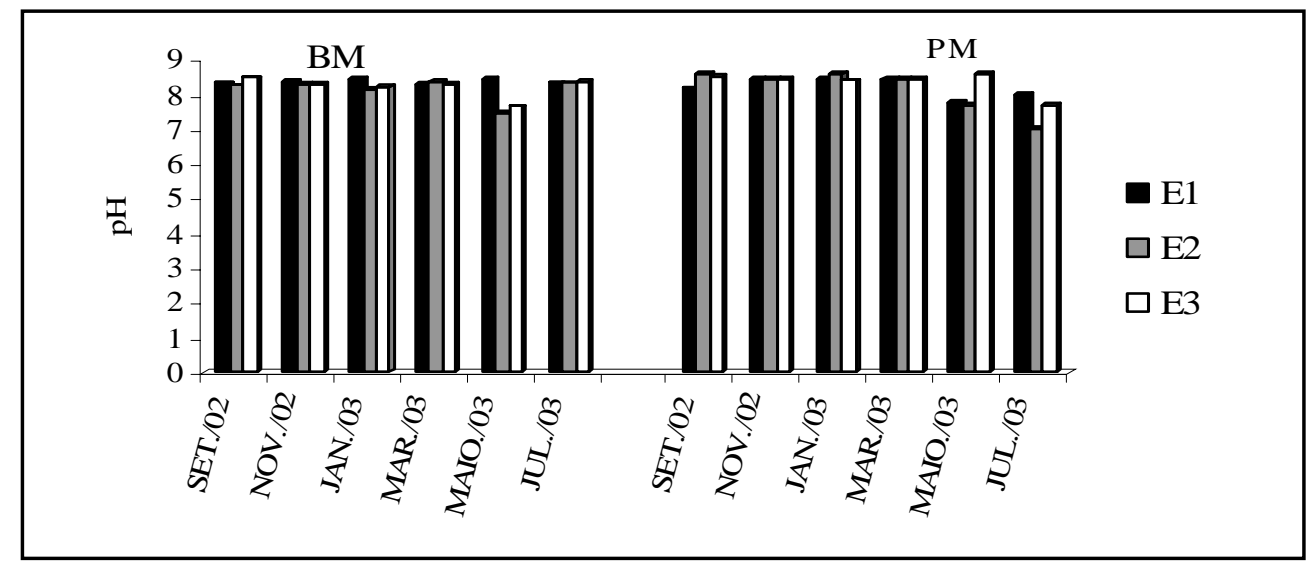

Figura 8 - Variação do pH nas estações 1, 2 e 3, durante as baixa-mares e preamares, nos períodos de estiagem e chuvoso, no estuário do rio Pisa Sal, Galinhos (RN, Brasil).

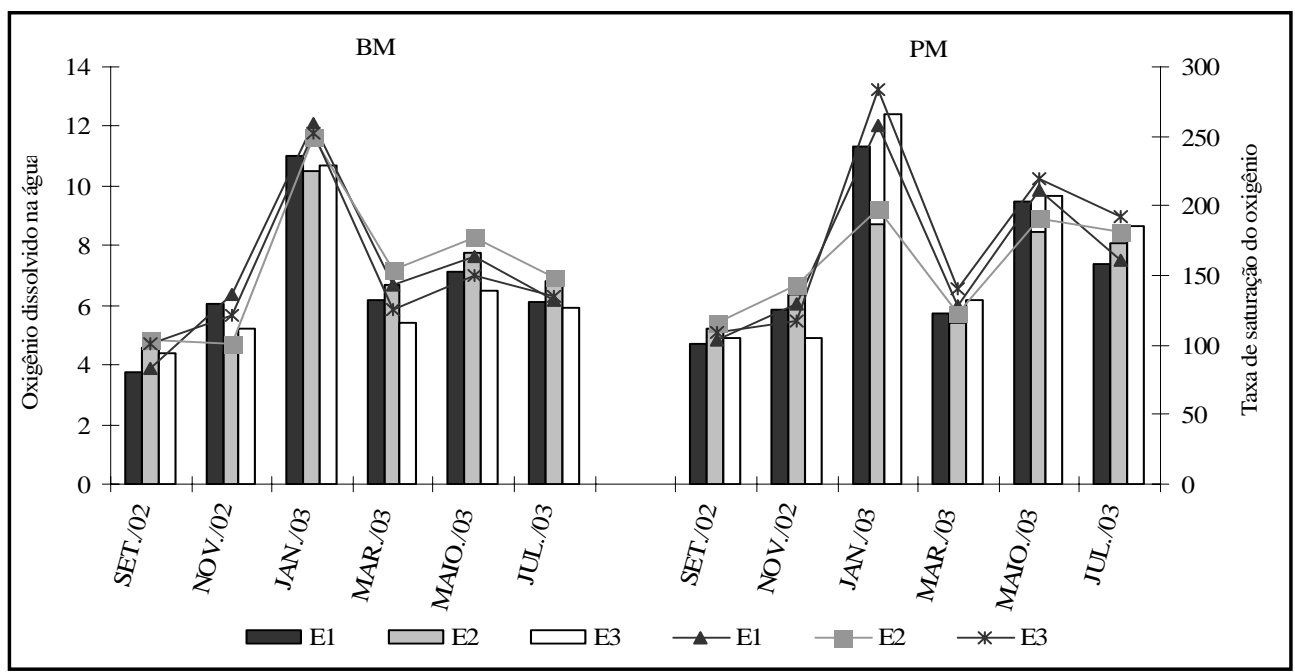

Figura 9 - Variação do oxigênio dissolvido na água $\left(\mathrm{ml} . \mathrm{L}^{-1}\right)$ e taxa de saturação do oxigênio (\%) nas estações 1, 2 e 3, durante as baixa-mares e preamares, nos períodos de estiagem e chuvoso, no estuário do rio Pisa Sal, Galinhos (RN, Brasil).

Tropical Oceanography, Recife, v. 33, n. 1, p. 39-55, 2005. 
Os valores de clorofila $a$ registrados na área estudada, em geral variaram entre 0,19 e 106,66mg.m ${ }^{-3}$, com mínimo em janeiro/02 na estação 3 e máximo em março/02 na estação 1 durante a baixa-mar, com uma amplitude de 106,47mg.m $\mathrm{m}^{-3}$ e média geral de 12,60mg.m $\mathrm{m}^{-3}$ (Fig. 10). Com relação as amplitudes houve um decréscimo da estação 1 para a 3 com valores de 104,94, 53,87 e $47,14 \mathrm{mg} . \mathrm{m}^{-3}$, respectivamente. Acompanha estes valores as médias dos valores de clorofila $a$ que foi de $19,46,9,80$ e $8,56 \mathrm{mg} \cdot \mathrm{m}^{-3}$.

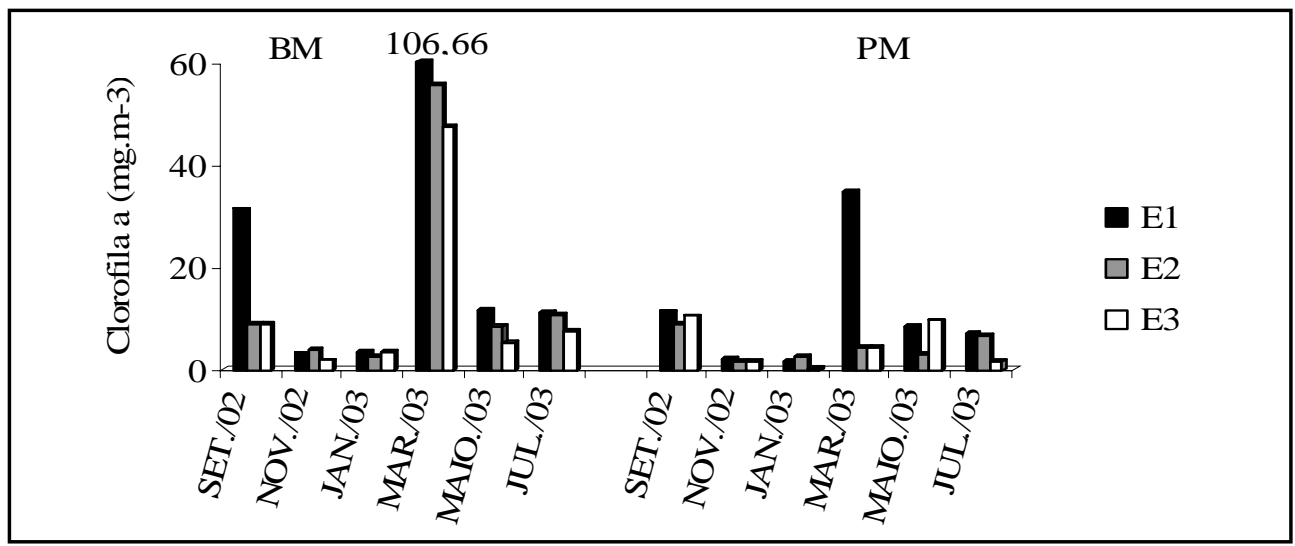

Figura 10 - Variação da clorofila $a\left(\mathrm{mg}^{-3} \mathrm{~m}^{-3}\right)$ nas estações 1 , 2 e 3, durante as baixamares e preamares, nos períodos de estiagem e chuvoso, no estuário do rio Pisa Sal, Galinhos (RN, Brasil).

Em relação a ACP, conforme demonstra o dendrograma abaixo, associa diretamente a clorofila $a$ com a transparência e salinidade da água e inversamente com os demais parâmetros abióticos (Fig. 11).

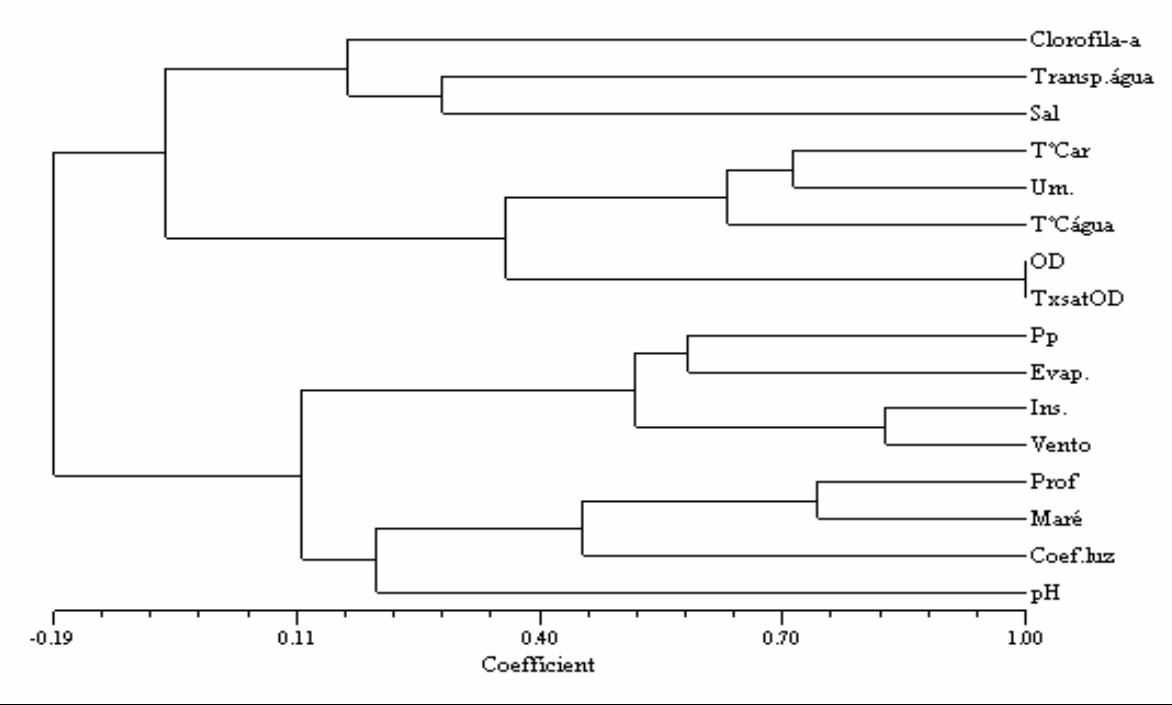

Figura 11 - Associação dos parâmetros ambientais estudados no estuário do rio Pisa Sal, Galinhos (RN, Brasil).

Tropical Oceanography, Recife, v. 33, n. 1, p. 39-55, 2005. 


\section{DISCUSSÃO}

Os estuários são considerados ecossistemas com alta produtividade, normalmente ricos em nutrientes necessários ao desenvolvimento do fitoplâncton, e o suprimento destes nutrientes continuamente renovado, sendo aportados pelos rios, mar e ainda pela lixiviação dos solos e áreas terrestres adjacentes (McLUSCK, 1989). Também, são caracterizados pela alta complexidade ecológica, reflexo de grande diversidade de funções atuantes. Desta forma, muitos dos seus atributos abióticos e bióticos mais importantes não são transitórios, e sim exclusivos (KETCHUM, 1983).

Costa et al. (1987/1989) consideram que além dos elementos nutrientes, as variáveis abióticas mais importantes no ecossistema marinho são luz, temperatura, salinidade, e o conhecimento destes parâmetros servem como requisito básico para todos os modelos ecológicos. Outras variáveis, também, são relevantes neste ambiente, como oxigênio dissolvido, um componente químico importante para os processos bioquímicos e biológicos, e o pH que está indiretamente ligado à quantidade de dióxido de carbono dissolvido decrescendo pela atividade fotossintética e aumentando devido a respiração (SANTOS, 2000).

Estes fatores físico-químicos, como também, condições meteorológicas e alternância das marés contribuem para a distribuição espacial e temporal de organismos fitoplanctônicos, afetando portanto, a clorofila a (FACCA et al., 2002; HITCHOCK; SMAYDA, 1977; PLATT; DENHAM, 1980; SMAYDA, 1980; COLE; CLOERN, 1984; CARRICK et al., 1993; KIRK, 1994; CLOERN, 1996; LUCAS et al., 1999a, b; BLEDSOE; PHLIPS, 2000 apud PHLIPS et al., 2002;).

A clorofila $a$ é o pigmento fisiologicamente mais importante estando presente em todos grupos vegetais (GRAHAM; WILCOX, 2000). Ademais, a relação entre a clorofila $a$ e os outros pigmentos que intervém na fotossíntese e entre seus produtos de degradação, proporcionam informações sobre o estado fisiológico do fitoplâncton e indiretamente, sobre a composição taxonômica de uma população (MARGALEF, 1991).

Koening (1983), também afirma que o método mais satisfatório para a medida dessa produção é o da biomassa fitoplanctônica que fornece dados reais sobre o potencial de produção biológica do ecossistema, para os demais níveis tróficos. Evidenciando aspectos do ambiente que permitam conduzir investigações e prever problemas de ecológicos (PASSAVANTE et al., 1987/1989).

Este parâmetro pode indicar a eutrofização do ambiente aquático, onde o principal efeito da eutrofização acelerada é a alteração da qualidade da água, com conseqüências para toda a biota (KENNISH, 1992 apud PERSICH et al., 1996).

Na área estudada, segundo a classificação de Passavante (2003), enquadra-se como ambiente eutrófico, entretanto no período chuvoso apresentou característica hipereutrófica, isto pode estar refletido às melhores condições ambientais para o desenvolvimento do fitoplâncton. Aspectos semelhantes são encontrados no estuário dos rios Gamtoons, Sundays e Kromme, na África do Sul (SNOW et al., 2000).

Para algumas regiões, o alto teor de clorofila $a$ em águas superficiais, na zona eufótica, está relacionado diretamente ao efeito da ressurgência ou de sedimentação e/ou adevcção de microfitobentos, além da influência marinha que o ambiente sofre, acentuando a transparência da água nas estações a jusante (PERISSINOTTO et al., 2002).

No estuário do rio Pisa Sal os valores mais altos da transparência estiveram relacionados à concentrações mais elevadas de salinidade, como comprovado na ACP, ainda, a luz interferiu de forma significativa na quantidade do pigmento fotossintético, uma vez que observou-se uma relação da transparência da água com a clorofila $a$. Ao contrário dos valores encontrados por Koening et al

Tropical Oceanography, Recife, v. 33, n. 1, p. 39-55, 2005. 
(2002) no estuário do rio Ipojuca, em Pernambuco, que os altos valores de clorofila $a$ coincidiu com a baixa luminosidade.

Inversamente proporcional à transparência da água, o coeficiente de extinção da luz, apresentou valores mais altos durante a preamar. Enquanto que espacialmente demonstrou um gradiente decrescente da estação mais a montante para a jusante, padrão este, semelhante ao observado no estuário do rio Botafogo no Estado de Pernambuco (ESKINAZI-LEÇA et al., 1984).

Outro parâmetro importante, afetado principalmente pelos fatores climatológicos e a grande influência da maré, é a salinidade (PHLIPS et al., 2002).

No estuário do rio Pisa Sal, de acordo com a ACP, demonstrou grande influência na distribuição da variação espaço-temporal dos pigmentos fotossintéticos, uma vez que segundo Fraga (1972), a salinidade é um dos fatores físico-químicos que influência as respostas funcionais dos organismos aquáticos, tais como crescimento, sobrevivência, reprodução e metabolismo. A sua estabilidade e/ou variação afeta, portanto, o crescimento, desenvolvimento e a fisiologia das algas (SMAYDA, 1983), funcionando geralmente como uma barreira ecológica para os organismos estenoalinos.

De acordo com o sistema do Simpósio de Veneza, em 1958, para a classificação de águas marinhas, o estuário do rio Pisa Sal apresentou o regime predominantemente hipersalino, porém algumas vezes com características eualinas. Condições semelhantes foram registradas por outros autores como Facca et al. (2002) na laguna de Venice - Itália; e Froneman (2002), no estuário Kasouga - África.

Em áreas tropical e subtropical, o regime de precipitação apresenta-se como sendo o maior fator controlador na dinâmica sazonal do fitoplâncton estuarino (SASSI, 1991). Flutuações sazonais da biomassa fitoplanctônica em estuários e áreas costeiras, têm sido freqüentemente associadas à precipitação pluviométrica (VALENTIN et al., 1985). Tendo em vista que interfere na biomassa, através do aporte de nutrientes, assim como pela alteração da qualidade óptica da água (TUNDISI; TUNDISI, 1976).

Vários trabalhos realizados têm demonstrado a influência e importância que a precipitação pluviométrica exerce sobre o aspecto físico-químico-biológico no ambiente aquático, datado desde a década de 50, como o trabalho de Steemann-Nielsen e Aabye e Jensen (1957).

A média histórica da pluviometria total, no litoral semi-árido do Rio Grande do Norte, referente aos anos 1980 a 2000, mostrou que o período de coleta ficou ligeiramente aquém da média histórica, com uma redução de $6,87 \%$ de chuvas.

Embora, segundo a ACP, não tenha indicado uma relação direta com a clorofila $a$, verificou-se que as chuvas caídas foram suficientes para provocar variações no parâmetro biológico, sendo o período chuvoso considerado mais representativo, com relação aos valores de biomassa (clorofila $a$ ).

Este fato, pode ser devido à entrada de água doce e a lixiviação na área, carreando grande quantidade de sais nutrientes devido à influência das chuvas, como ocorre na zona costeira de Pernambuco (ESKINAZI-LEÇA et al., 1997) e no estuário do rio Dollard, na Holanda (STAATS et al., 2001).

Outro excelente parâmetro indicador da qualidade ambiental no ecossistema aquático é o teor de oxigênio dissolvido na água, pois segundo McLusck (1971), ressalta a abundância do fitoplâncton como uma das principais fontes desse gás, considerando também, o fluxo de água doce e salgada, e, ainda, a absorção através da atmosfera.

O teor de oxigênio na superfície da água encontra-se em equilíbrio com o ar atmosférico, ao passo que os processos químicos, resultantes de fenômenos biológicos, promovem um desvio dos valores de saturação para mais ou para menos. O valor efetivo do teor de oxigênio dissolvido,

Tropical Oceanography, Recife, v. 33, n. 1, p. 39-55, 2005. 
encontrado na água apresenta, portanto, a expressão da interação de todos os fenômenos ocorridos na mesma (SANTOS, 2000).

Além disso, é um importante indicador de áreas poluídas uma vez que baixas concentrações poderão indicar uma poluição química, física ou biológica, e valores muito elevados, processos de eutrofização, que também poderão ter conseqüências negativas como depleção noturna o que poderá provocar a migração ou morte de animais de grande importância no elo trófico como econômico (FLORES MONTES, 1996).

Eskinazi-Leça et al. (1984) e Costa e Macêdo (1987/1989) relacionam valor baixo de oxigênio dissolvido a um maior consumo, decorrente da oxidação da matéria orgânica, pelas bactérias e aos intensos processos biológicos e químicos. De acordo com Cavalcanti et al. (1981), a fotossíntese, as trocas gasosas existentes entre a água e a atmosfera, a respiração, a decomposição aeróbica da matéria orgânica, a temperatura e a salinidade são fatores que estão estreitamente relacionados ao teor de oxigênio no ambiente aquático.

No estuário do rio Pisa Sal a relação inversa da clorofila $a$ com o oxigênio dissolvido e taxa de saturação do oxigênio, pode estar relacionado com a temperatura da água e a salinidade, visto que, normalmente, quanto maior for o nível deste último parâmetro, menor será a solubilidade do gás.

Em áreas sob forte influência de maré, como os estuários, a profundidade, também, é considerada um parâmetro importante, tendo em vista que há desprendimento dos sais nutrientes retidos no sedimento, dispersando-os na coluna d'água, enriquecendo a camada fótica, uma vez que conduz o transporte e a troca de materiais orgânicos e inorgânicos (TUNDISI, 1970). Segundo Smayda (1983), o material em suspensão nas águas estuarinas contém partículas orgânicas e inorgânicas, capazes de competir com o fitoplâncton, absorvendo parte da luz de determinadas faixas no espectro e refletindo parte da luz.

Em estuários pouco profundos, a ressuspensão dos sedimentos de fundo é causada muitas vezes pelo vento, segundo Pedersen et al. (1995), a velocidade mínima necessária para criar esta ressuspensão é estimada em 3m.s ${ }^{-1}$. Já Jonge e Beusekom (1995) no estuário do rio Sem, na Alemanha, registrou uma velocidade média de até $6 \mathrm{~m} . \mathrm{s}^{-1}$ como um importante fator nos processos de ressuspensão.

No Sistema Estuarino Galinhos-Guamaré, Silveira (2002) apud Grigio (2003), registrou a velocidade média anual dos ventos, conforme o histórico de 20 anos, de $5,7 \mathrm{~m} . \mathrm{s}^{-1}$. Durante o período estudado a velocidade mínima foi de $4,7 \mathrm{~m} . \mathrm{s}^{-1}$, portanto com capacidade suficiente de ressuspender 0 sedimento. Sendo comprovado, também, pelos baixos valores de transparência ocorrido durante o período de estiagem, coincidindo com ventos mais fortes.

Segundo a ACP, no ambiente estuarino do rio Pisa Sal foi constatado, que a profundidade, maré e pH tiveram uma correlação inversa com a clorofila $a$. Em visto que além de pouco profundo, não sofre praticamente de influência de água doce para então interferir na salinidade e a transparência que estão correlacionados diretamente com a clorofila $a$, comprovando uma maior influência oceânica.

\section{CONCLUSÕES}

- Altos valores de salinidade registrados no estuário do rio Pisa Sal caracterizaram a área como ambiente eualino à hipersalino, indicando uma pequena influência dos aportes pluvio-fluvial, maior insolação e evaporação.

- Este ambiente se autorenova, apesar dos impactos antrópicos, devido a entrada de águas marinhas e a intensidade da velocidade dos ventos que influenciam na oxigenação da água.

Tropical Oceanography, Recife, v. 33, n. 1, p. 39-55, 2005. 
- A biomassa (clorofila a) foi mais elevada durante o período chuvoso, apresentando uma variação sazonal influenciada principalmente pela transparência da água e salinidade.

- O estuário do rio Pisa Sal foi considerado eutrófico, com ocorrência de hipereutrofização no período chuvoso, provavelmente em decorrência dos impactos antrópicos, parâmetros climatológicos e transparência da água.

\section{REFERÊNCIAS BIBLIOGRÁFICAS}

ANDRADE, G. O.; LINS, R. C. Os climas do Nordeste. In: VASCONCELOS SOBRINHO, J. (Ed.). As regiões naturais do Nordeste, o meio e a civilização. Recife: CONDEPE, 1971. p. 95138.

ARAGÃO, J. O. R. de. Fundamentos de meteorologia e relção oceano-atmosfera. [S.l.], o autor, 2000. $60 \mathrm{p}$.

BROCE, D. A S. Importação e exportação de carbono orgânico sob forma particulada através da Barra Sul do Canal de Santa Cruz, Itamaracá - PE, Brasil. 1994. 270 f. Dissertação (Mestrado em Oceanografia Biológica) - Departamento de Oceanografia, Universidade Federal de Pernambuco, Recife, 1994.

CAVALCANTI, L. B.; MACÊDO, S. J.; PASSAVANTE, J. Z. O. Estudo ecológico da região de Itamaracá, Pernambuco-Brasil. XXI. Caracterização do Canal de Santa Cruz em função dos parâmetros físico-químicos e pigmentos fotossintéticos. Trabalhos Oceanográficos [da] Universidade Federal de Pernambuco, Recife, v. 16, p. 157-216, 1981.

CESTARO, L. A. Os elementos do clima de Galinhos, RN como recursos naturais à disposição do homem. Caderno Norte Riograndense - Temas Geográficos, Natal, v. 8, n. 1, p. 13-28, 1994.

COSTA, K. M. P.; MACEDO, S. J. Estudo hidrológico do rioTimbó (Pernambuco-Brasil). Trabalhos Oceanográficos Oceanográficos, Recife, v. 20, p. 7-34, 1987/1989.

COUTINHO, A M. A Fundamentos de climatologia. Recife: EDUFPE, 1991. 44 p. (Notas e Comunicações de Geografia; Série B: Textos didáticos, n. 10).

ESKINAZI-LEÇA E.; SILVA-CUNHA, M. G. G.; KOENING, M. L.; MACEDO, S. J.; COSTA, K. M. P. Variação espacial e temporal do fitoplâncton na Plataforma Continental de Pernambuco Brasil. Trabalhos Oceanográficos, Recife, v. 25, p. 1-16, 1997.

ESKINAZI-LEÇA, E.; BARROS-FRANCA, L. M. MACEDO, S. J. Estudo ecológico da área de Itamaracá (Pernambuco-Brasil) XXIV. Standing-stock do fitoplâncton do estuário do rio Botafogo, durante Janeiro/dezembro/75. Trabalhos Oceanográficos, Recife, v. 18, p. 153-192, 1984.

FACCA, C.; SFRISO, A.; SOCAL, G. Changes in abundance and composition of phytoplankton and microphytobenthos due to increase sediment fluxes in the Venice lagoon, Italy. Estuarine, Coastal and Shelf Science, London, v. 54, p. 773-792, 2002.

Tropical Oceanography, Recife, v. 33, n. 1, p. 39-55, 2005. 
FLORES MONTES, M. de J. Variação nictemeral do fitoplâncton e parâmetros hidrológicos no canal de Santa Cruz, Itamaracá, PE. 1996. 201 f. Dissertação (Mestrado em Oceanografia Biológica) - Departamento de Oceanografia, Universidade Federal de Pernambuco, Recife, 1996.

FRAGA, F. El água marina. In: CASTELLI, J. Ecologia marina. Caracas: Fundación La Salle de Ciencias Naturales, 1972. p. 67-99.

FRONEMAN, P. W. Responsa of the plankton to three different hidrological phases of the temporarily open/closed Kasouga Estuary, South África. Estuarine, Coastal and Shelf Science, London, v. 55, p. 535-546, 2002.

GOMES, H. R.; GOES, J. L.; SAINO, T. Influence of physical processe and freshwater discharge on the seasonality of phytoplankton regime in the bay of Bengal. Continental Shelf Research, London, v. 20, p. 313-330, 2000.

GRAHAM, L. E.; WILCOX, L. W. Algae. New Delhi, Prentice Hall, 2000. 640 p.

GRASSHOFF, F. K.; ENRHARDT, M.; KREMLING, K. Methods of seawater analysis. 2. ed. Nova Iorque: Verlag Chemie, 1983. 419 p.

GRIGIO, A. M.; AMARO, V. E.; VITAL, H.; DIODATO, M. A. Método de análise da evolução da linha de costa com base em produtos de sensoriamento remoto e sistema de informação geográfico: município de Guamaré, Estado do Rio Grande do Norte, Nordeste do Brasil. ISPRS Journal of Photogrammetry \& Remote Sensing da International Society for Photogrammetry and Remote Sensing, [S.1.], 2003. (no prelo).

IDEMA. Avaliação e ações prioritárias para a conservação da biodiversidade da zona costeira e marinha: caracterização dos ecossistemas costeiros dos Estados: Rio Grande do Norte, Ceará e Piauí. Natal: Governo do Estado do Rio Grande do Norte, 1999. 50 p. (Base de Dados Tropical BDT).

JONGE, V. N.; BEUSEKON, J. E. E. Wind and tide induced resuspension of sediment and microphytobenthos from tidal flats in the Ems estuary. Liminology and Oceanography, Lawrence, v. 40, n. 4, p. 766-778, 1995.

KETCHUM, B. H. (Ed.). Estuaries and enclosed seas. Amsterdam: Elsevier, 1983. 500 p. (Ecosytems of the World, 26).

KOENING, M. L. Biomassa e fracionamento do fitoplâncton em viveiros de cultivo de peixes na ilha de Itamaracá (Pernambuco - Brasil). 1983. 139 f. Dissertação (Mestrado em Criptógamos) Departamento de Botânica, Universidade Federal de Pernambuco, Recife, 1983.

KOENING, M. L.; ESKINAZI-LEÇA, E.; NEUMANN-LEITÃO, S.; MACÊDO, S. J. de. Impactos da construção do Porto de Suape sobre a comunidade fitoplanctônica no estuário do rio Ipojuca (Pernambuco-Brasil). Acta Botanica Brasílica, São Paulo, v. 16, n.4, 2002.

MARGALEF, R. Ecologia. 7. ed. Barcelona: Omega, 1991. 951 p.

Tropical Oceanography, Recife, v. 33, n. 1, p. 39-55, 2005. 
McLUSCK, D. S. Ecology of estuaries. London: Heinemann Educational Books, 1971. 144 p.

McLUSCK, D. S. The estuarine ecosystem. 2. ed. Glasgow: Blackie, 1989. cap. 1, p. 1-39.

MIRANDA, L. B.; CASTRO, B. M.; KJERFVE, B. Princípios de oceanografia física de estuários. São Paulo: EDUSP, 2002. 414 p. (Acadêmica, n. 42).

MMA. Macrodiagnóstico da zona costeira do Brasil na escala da União. Brasília: MMA/PNMA, 1996. 280 p.

PASSAVANTE, J. Z. de O. Produção fitoplanctônica do estuário do rio Capibaribe (Recife, Pernambuco, Brasil). In: CONGRESSO NORDESTINO DE ECOLOGIA. Resumos... Recife. 2003. CD-ROM.

PASSAVANTE, J.Z.O.; GOMES, N. A.; ESKINAZI-LEÇA, E.; FEITOSA, F. A. do N. Variação da clorofila a do fitoplâncton na Plataforma Continental de Pernambuco. Trabalhos

Oceanográficos, Recife, v.20, p.145-154, 1987/1989

PEDERSEN, O. B.; CHRISTIANSEN, C.; AUREN, M. B. Wind induced long term increase and short term flutuations of shallow waters suspended mater and nutrient concentrations, RingJbind Fjord, Denmark. Ophelia, Heldingor, v. 41, p. 273-287, 1995.

PERISSINOTTO, R.; NOZAIS, C.; KIBIRIGE, I. Spatio-temporal dynamics of phytoplankton and microphytobenthos in a South African temporally-open estuary. Estuarine, Coastal and Shelf Science, [S.l.], v. 55, p. 47-58, 2002.

PERSICH, G. R.; ODEBRECHT, C.; BERGESH, M.; ABREU, P. C. Eutrofização e fitoplâncton: comparação entre duas enseadas rasas no estuário da lagoa dos Patos. Atlântica, Rio Grande, v. 18, p. 27-41, 1996.

PHLIPS, E. J.; BADYLAK, S.; GROSSKOPF, T. Factors affecting the abundance of phytoplankton in a restricted subtropical lagoon, the Indian river lagoon, Florida, USA. Estuarine, Coastal and Shelf Science, London, v. 55, p. 385-402, 2002.

POOLE, H. H.; ATKINS, W. R. G. Photo-electric measurements of submarine illumination throughout the year. Journal of the Marine Biological association of the United Kingdom, Plymouth, v. 16, p. 234-297, 1929.

SANTOS, M. L. S. Influência dos rios Amazonas e Pará sobre a biomassa fitoplanctônica. 2000. 105 f. Dissertação (Mestrado em Oceanografia) - Departamento de Oceanografia, Universidade Federal de Pernambuco, Recife, 2000.

SASSI, R. Phytoplankton and environmental factor in the Paraíba do Norte river estuary, northeastern Brazil: composition, distribution and quantitative remarks. Boletim do Instituto Oceanográfico, São Paulo, v. 39, n. 2, p. 93-115, 1991.

SMAYDA, T. J. The phytoplankton of estuaries. In: KETCHUM, B. H. (Ed.). Estuaries and enclosed seas. Amsterdam: Elsevier Scientific, 1983. cap. 4. p. 65-101.

Tropical Oceanography, Recife, v. 33, n. 1, p. 39-55, 2005. 
SNOW, G. C.; ADAMS, J. B.; BATE, G. C. Effect of river flow on estuarine microalgal biomass and distribution. Estuarine, Coastal and Shelf Science, London, v. 51, p. 255-266, 2000.

SOBRINHO, J. (Ed.). As regiões naturais do Nordeste, o meio e a civilização. Recife: CONDEPE, 1971. p. 95-138.

STAATS, N.; DECKERE, E. de; KORNMAN, B.; LEE, W. van der; TERMAAT, R.; TERWINDT, J.; WINDER, B. de. Observations on suspended particulate matter (SPM) and microalgae in the Dollard estuary, the Netherlands: importance of late winter ice cover of the intertidal flats.

Estuarine, Coastal and Shelf Science, London, v. 53, p. 297-306, 2001.

STEEMANN-NIELSEN, E.; AABYE, J. Primary oceanic production yhe autotrophic production of organic matter in the oceans. Galathea Rep., [S.l.], v. 1, p. 49-136, 1957.

STRICKLAND, J. D. H.; PARSONS, T. R. A practical handbook of seawater analysis. 2. ed. Bulletin Fisheries Research board of Canada, Ottawa, n. 167, p. 1 - 211, 1972

TEIXEIRA, C. Introdução aos métodos para medir a produção primária do fitoplâncton marinho. Boletim do Instituto Oceanográfico de São Paulo, São Paulo, v. 22, p. 59-92, 1973.

TUNDISI, J. G. O plâncton estuarino. Contribuições Avulsas [do] Instituto Oceanográfico da Universidade de São Paulo, São Paulo, n. 19, p. 1-22, 1970. (Série Oceanografia Biológica).

TUNDISI, J. G.; TUNDISI, T. M. Produção orgânica em ecossistemas aquáticos. Ciência e Cultura, São Paulo, v. 28, n. 8, p. 861-7, 1976.

UNESCO. International Oceanographic Table. Wormly: Optichrome, 1973. 141 p. v.2.

VALENTIN, J. L.; SILVA, N. M. L; BASTOS, C. T. B. Les diatomées dans upwelling de de Cabo Frio (Brésil): liste d’espéces et étude écologique. Journal Plankton Research, Oxford, v.7, n.3, p. 313-337, 198 
Tropical Oceanography, Recife, v. 33, n. 1, 2005. 